\title{
DIE EFFEK VAN SOWJET EN OOS-EUROPESE VERANDERINGS OP KOMMUNISTIESE EN SOSIALISTIESE DENKE IN SUID-AFRIKA
}

\author{
G.J. Rossouw \\ Departement Filosofie \\ Randse Afrikaanse Universiteit \\ JOHANNESBURG
}

\begin{abstract}
The purpose of this anicle is to determine from a philosophical point of view the extent to which socialist and communist organizations in South Africa have been influenced by the changes that have occurred in Eastem Europe. In order 10 make such an assessment, it is necessary to identify' the nuture of the events that occurred in Eastern Europe and the Soviet Union. This aspect is discussed in the first section of this article. Following this it is angted that different socialist and or communist groups have been influenced in different ways by the East-bloc events. In order to demonstrate this difference, the way in which three different political groups in South Africa have been influenced will be highlighted. These groups are the ANC (and its partners the UDF and COSATO), the SACP and the Black Consciousness Movements (like AZAPO). In the concluding section a few observations on the implications of the Eastern European changes for the political and economic debate in South Africa are oulined.
\end{abstract}

\section{INI .EIDEND}

In teenstelling met die oproep van Marx en Engels se Kommunistiese manifes, naamlik "Workers of the world, unite", het 'n slagspreuk van 'n betoger tydens die 72ste herdenking van die Bolsjewistiese Revolusie wat onlangs in Moskou gehou is, gelui "Workers of the world, we apologize". Agter hierdie slagspreuk skuil die opvatting dat sosialisme en kommunisme totaal misluk het en dat dit moet plek maak vir'n totaal andersoortige politieke en ekonomiese stelsel.

Hierdie selfde beoordeling van die gebeure in die Oos-blok is ook besonder gewild in die Westerse wêreld. Daar word gemeen dat sosialisme 'n mislukte eksperiment is, en dat daar 'n haastige oorgang na liberale demokrasie en vryemark-ekonomie in OosEuropa gaan plaasvind. 'n Meer genuanseerde kyk na die gebeure in die Sowjet-Unie en in Oos-Europa toon egter aan dat dit 'n ietwat simplistiese en oordrewe optimistiese opvatting is.

Die doel van hierdie artikel is om vanuit 'n filosofiese hoek te gaan kyk hoedanig 
sosialistiese en kommunistiese denkraanwerke in Suid-Afrika spesifiek deur die veranderinge in die Oos-Europa geraak is. Daar sal om hierdie rede nie probeer word om 'n politieke analise van die Suid-Afrikaanse samelewing te maak nie. Die klem sal veel eerder val op die denkverskuiwings wat in kommunisties- en sosialistiesgeöriënteerde groepe plaasgevind het tot en met die eerste kwartaal van 1990. Verder sal spesifiek gefokus word op die wyse waarop die leierskap van sodanige groepe op die veranderings in die Oos-blok en die Sowjet-Unie gereageer het. (Die leierskapelement in hierdie groepe was opsigtelik meer sensitief vir die verandering in die Oosblok as die gewone lede van van hierdie organisasies.) Vir dié doel sal daar 'n studie gemaak word van belangrike dokumente van die verskillende politieke groeperinge dokumente wat in reaksie op die Oos-blokgebeure geformuleer is.

Ten einde ' $n$ bepaling te maak van die effek van die Oos-blokveranderinge op sosialistiese en kommunistiese denkraamwerke in Suid-Afrika, is dit allereers nodig om 'n fyner bepaling van die aard van die gebeure in Oos-Europa te maak. Dit sal in die eerste deel van hierdie artikel gedoen word. Daarna sal daar aangetoon word dat politieke groepe wat in Suid-Afrika met sosialistiese en/of kommunistiese opvattings werk, verskillend deur die Oos-blokgebeure beïnvloed is. Ten einde die verskille in die mate van beïnvloeding aan te dui, sal drie groepe in die Suid-Afrikaanse politiek geïdentifiseer en bespreek word, naamlik die ANC (waarby sy binnelandse vennote soos COSATU en die UDF ingesluit is), die SAKP en derdens die swartbewussynsgroeperinge (waaronder AZAPO tel). Ten slotte sal daar dan 'n aantal opmerkings gemaak word oor die betekenis van die Oos-blokveranderinge vir die politieke en ekonomiese debat in Suid-Afrika.

\section{DIE AARI) VAN DIE VERANIERINGE IN DIE OOS-BLOK}

Stojanovic dui in sy boek Perestroika: From Marxism and Bolshevism to Gorbachev (1988), aan dat Marx hom in sy filosofie te onkrities aangesluit het by Hegel se optimistiese opvatting oor die dialektiese vooruitgang van die geskiedenisproses. Hy het nie voldoende rekening gehou met wat die neo-Marxisme later sou tipeer as die negatiewe dialektiek, dit wil sê die negatiewe of vervreemdende ontwikkeling wat binne enige moderniserende sisteem kan plaasvind.

Die gebeure in die Oos-blok kan dan ook met reg getipeer word as 'n erkenning dat die negatiewe dialektiek sy tol binne die kommunistiese tradisie geëis het. Die vervreemding waarteen Marx gestry het, het binne die sisteem wat Lenin gestig het om die kapitalistiese vervreemding teen te werk, juis erger vorme begin aanneem as dié waarteen Marx oorspronklik gestry het. 
Onder die begrip vervreemding moet verstaan word dat ' $n$ situasie ontstaan waarin die mens (die burger in die samelewing) nie meer die subjek van handeling is nie, maar deur 'n mensgeskape objek of sisteem gedomineer word. Die diepste grond van die verandering wat in die Oos-blok plaasgevind het, moet dan ook juis in hierdie belewing van vervreemding onder die burgers in die kommunistiese Oos-blok gesoek word. Die feit dat die oorgrote meerderheid van die bevolking beleef het dat hulle sowel ekonomies as polities vervreem is, het nie alleen net persoonlike motivering lamgelê nie, maar het ook die ekonomie nadelig geraak.

Die uitweg uit hierdie situasie wat ekonomies onleefbaar en polities moreel onhoudbaar geword het, is gesoek in 'n strategie waar die mark die muntkant en demokrasie die kruiskant van dieselfde strategie is. Via 'n meer markgerigte ekonomie moes ekonomiese vervreemding opgehef word ten einde 'in gemotiveerde arbeidsmag en 'n gesonde ekonomie te skep. Via demokrasie moes politieke vervreemding opgehef word ten einde verantwoordelike burgers te skep, wat die samelewing in die toekoms van soortgelyke verval tot vervreemding kon vrywaar.

Hierdie basiese strategie as antwoord op vervreemding is egter op verskillende wyses aangewend. Eerstens was daar die groep wat wou aantoon dat kommunistiese sosialisme nie as die oorsaak van die vervreemding beskou kon word nie - dit was eerder in die bestuur en toepassing van die kommunisme waar die fout gesoek moes word. Hierdie benadering het daartoe gelei dat bepaalde sondebokke vir die deformering van kommunisme aangetoon is (waaronder Stalin die hoofsondebok was) en dat daar weer teruggegryp is na die vaders van die idee van kommunisme ten einde met die outentieke interpretasie van die Marxistiese kommunisme vorendag te kom. Gorbachev met sy beroep op Lenin om perestroika en glasnost te legitimeer is 'n sprekende voorbecld van hierdie benadering (vgl. Gorbachev, 1987:25-26).

'n Tweede reaksie binne die kaders van die kommunistiese denke was om die filosofie onderliggend aan die kommunistiese denke te blameer vir die deformasie van kommunisme. Denkfoute en verkeerde aannames van veral Marx en Lenin het volgens hierdie siening aanleiding gegee tot die uiteindelike vervreemding in die kommunistiese stelse!. Die implikasie van hierdie opvatting is dat die Marxisties-Leninistiese teorie grondig aangevul of in hersiening geneem moet word ten einde sosialistiese kommunisme weer 'n lewensvatbare toekoms te gee. Svetozar Stojanovic is 'n goeie voorbeeld van hierdic benadering as hy sê: "In my opinion the only Marxism genuinely alive today is both fragmentary and radical - revisionist" (1988:13).

'n Derde groep het egter daarvoor gekies om die keuse vir 'n markgeoriënteerde ekonomic en vir demokrasie buite die kaders van die Marxistiese tradisie te maak. 'Trouens, die kommunistiese denksisteem is deur hulle as die oorsaak van die ver- 
vreemding beskou. Die keuse vir demokrasie en vir die markgeoriënteerde ekonomie was daarom 'n keuse teen kommunisme. In teenstelling met die eerste groep wat kommunisme wou rehabiliteer en die tweede groep wat kommunisme in hersiening wou neem, het hierdie derde groep kommunisme as sodanig verwerp.

Daar word dikwels die anname gemak dat hierdie derde groep se verwerping van kommunisme outomaties 'n keuse vir' $n$ liberaal-demokratiese vryemarksisteem impliseer. Dit is egter 'n oorhaastige aanname. Die feit dat die Sweedse model van demokratiese sosialisme tans ernstige aandag geniet in Oos-Europa asook die uitsprake van die nuwe Tsjeggo-Slowaakse leier, Havel, dui 'n op veel meer versigtige benadering. Havel maak enersyds geen geheim van sy keuse vir die mark en vir demokrasie nie, maar andersyds wys hy tog ook daarop dat sy keuse gepaard gaan met morele besinning. Die ekonomie moet wel groeiend wees, maar moet nie in gulsigheid ontaard nie. Daar moet steeds 'n sosiale sensitiwiteit vir die belange en welsyn van die breë bevolking wees (vgl. Nagorski, 1990:13 en Pederson, 1990:8-9).

Daar sal nou vervolgens aangetoon word hoe hierdie bostaande reaksies op die krisis van sosialisme ook in Suid-Afrika uitgekring het.

\section{DIE EFFEK VAN OOS-BLOKVERANDERINGS OP SOSIALISTIIESE EN KOMMUNISTIESE DENKE IN SUID-AFRIKA}

Die feit dat beide voorstaanders en teëstanders van sosialistiese kommunisme in die Oos-blok konsensus oor die krisis van die sosialistiese ekonomiese stelsel en die kommunistiese regeerstelsel het (vgl. Latey, 1989:131), sou 'n mens laat vermoed dat sosialistiese en kommunistiese denkers in Suid-Afrika die lesse van Oos-Europa as geloofwaardig sou beskou en daarom ernstig sou opneem. Tog wissel die mate waarin erns gemaak word met die Oos-Europese situasie aansienlik onder sosialistiese en kommunistiese groepe in Suid-Afrika. Heribert Adam is dan ook van mening dat die invloed van Oos-blokveranderings op Suid-Afrikaanse denkers geïnhibeer word deur die heersende onregverdige politieke bestel in Suid-Afrika. Hy sê:

\footnotetext{
As long as the gross incquality and historical exclusion of the majority persist, hopes that Eastern European developments would also prove infectious in South Africa remains wishfu thinking (Adam, 1990:8).
}

Ten einde aan te toon tot hoe 'n mate die reaksie van verskillende groepe op die Oosblokgebeure in Suid-Afrika verskil, sal daar vervolgens aangetoon word wat die reaksie van onderskeidelik die ANC, die SAKP en die swartbewussynsgroepe op hierdie gebeure is. 


\subsection{Die ANC}

Wanneer die grondwetlike riglyne wat die ANC in 1988 gegee het, ondersoek word, lyk dit of die Oos-blokveranderinge 'n belangrike invloed op die denke in die ANC gehad het, aangesien sowel die uitbouing van demokratiese regte as die erkenning van sekere markbeginsels daarin opgeneem is. Tog moet alle krediet vir hierdie ontwikkeling nie oorhaastig aan Oos-Europa gegee word nie.

Betreffende die erkenning van 'n wye reeks demokratiese regte in hierdie konstitusionele riglyne, moet daar daarop gelet word dat 'n groot deel van dié regte alreeds in die Freedom Charter van 1955 vermeld is. Daar sou dus geargumenteer kan word dat die formulering en uitbreiding van demokratiese regte die vrug van ontwikkeling in 'n reeds lank gevestigde tradisie is.

Diesclfde sou egter nie van die ekonomiese riglyne van die ANC in sy nutste grondwetlike riglyne gesê kan word nie. In teenstelling met die redelik eksplisiete verwysing na die nasionalisering en sosialisering van die land se bates in die Freedom Charter, kom daar bykans geen verwysing na nasionalisering in die nuwe grondwetlike riglyne voor nie. Die klem val eerder op 'n ekonomie waarin daar'n verskeidenheid vorme van eienaarskap voorkom en waarin markkragte toegelaat sal word om te funksioneer. Dat die basiese oognerk van die Freedom Charter se ekonomiese riglyne egter nog behou word, blyk daaruit dat die nuwe riglyne daarvoor pleit dat die opbrengs van die ekonomie deur die staat sodanig bestuur moet word dat dit die sosiale welsyn van die land se totale bevolking sal dien. Dit blyk duidelik wanneer verklaar word dat " $(t)$ he state shall ensure that the entire economy serves the interests and well-being of the entire population" (Van Holdt, 1990:49).

Uit die nuwe ekonomiese riglyne blyk dit dat die negatiewe ekonomiese les wat OosEuropa en die Sowjet-Unie rakende nasionalisering geleer het, ook deur die ANC ernstig geneem word. Daar word aanvaar dat slegs 'n groeiende ekonomie in die land se basiese welsynsbehoeftes kan voorsien en dat nasionalisering vermy moet word, aangesien dit juis stagnering van die ekonomie tot gevolg kan hê.

Ernstige sosialiste in die geledere van die ANC-SAKP alliansie is dan ook juis verontrus oor hierdie ontwikkeling in die ANC se jongste konstitusionele riglyne, aangesien dit na hulle mening 'n verloëning van sosialisme impliseer. Dit blyk duidelik wanneer Daryl Glaser(1988:30) in sy kommentaar op hierdie nuwe riglyne sê:

But there are other - and more worrying - possibilities. One is that socialism has been abandoned as a serious goal for the foresecable future, and displaced from the agenda of contemporary political discussion and mobilisation. 
Hierdie tempering van sosialisme word ook weerspieël in die sienings van die ANC se binnelandse vennote soos COSATU. Alex Erwin, die prominente ekonoom in COSATU, gee ook erkenning aan die ekonomiese lesse van die Oos-blok as hy erken dat massiewe nasionalisering nie die land se ekonomiese probleme kan oplos nie. Hy is egter van mening dat die vryemark eweneens nie by magte is om die skewe verspreiding van welvaart in die Suid-Afrikaanse ekonomie te korrigeer nie. Dit blyk duidelik as hy sê: "Our solutions lie neither in free market capitalism nor in centrally planned command economy socialism" (Erwin, 1990:26). Erwin kies uiteindelik steeds 'n vorm van sosialistiese ekonomie, maar dan 'n sosialisme wat die mark wil benut en wat ekonomiese groei kan verseker. Die rede waarom hy steeds hierdie nuwe ekonomie as sosialisties tipeer is omdat "the economy functions within the parameters of polically decided strategic plans" (Erwin, 1990:26).

Die nuwe grondwetlike riglyne en Erwin se uitsprake oor 'n getemperde vorm van sosialisme, moet egter nie lei tot 'n oorhaastige konklusie dat die gedagte van massiewe nasionalisering en sosialisering totaal prysgegee is in die ANC en sy binnelandse vennote naamlik COSATU en die UDF nie. In sowel COSATU as die UDF is daar duidelike spanning tussen die sogenaamde 'charteriste' aan die een kant en die sogenaamde 'werkeriste' aan die ander kant. Dit is natuurlik net die eersgenoende groep wat die bostaande denkverskuiwings in die leierskapsgeledere van die ANC steun. Die sogenaamde werkeristiese of Trotskyistiese element in COSATU daarenteen oefen toenemende druk uit op die COSATU-leierskap om 'n groter mate van werkersbeheer in hul ekonomiese voorstelle te inkorporeer (vgl. Davies-Webb, 1989:83-85). Ook binne die UDF-geledere is die gedagte van nasionalisering steeds prominent. By die onlangse Oos-Kaaplandse jaarvergadering van die UDF is besluit dat: "Nationalisation should be the bottomline of the socio-economic policy of a post apartheid South Africa" (Anon, 1990:25).

Hieruit blyk dat die Oos-Europese klem op die belangrikheid van die mark in die ekonomie ook deur die topstruktuur van die ANC en COSATU ernstig geneem is. Tog impliseer dit nie dat sosialisme daarmee laat vaar is nie. Wat wel gebeur het, is dat die klem vanaf nasionalisering en sosialisering verskuif het na 'n demokraties-gerigte sosialistiese ekonomie. Hierdie nuwe denke oor die ekonomie het egter nog nie in die ANC en sy vennote algemene aanvaarding gevind nie. Die meeste wat daarom oor die invloed van Oos-Europese veranderings op sosialistiese denke in die ANC gesê kan word, is dat dit die debat oor sosialisme meer brandend en meer innoverend as ooit tevore gemaak het. 


\subsection{SAKP}

Vir die peiling van die effek van Oos-blokveranderinge op die kommunistiese en sosialistiese denke van die SAKP, is veral twee onlangse publikasies van die SAKP van besondere belang. Eerstens is daar The path to power, die beleidsdokument van die SAKP wat by die sewende kongres van die party in Julie 1989 in Kuba aanvaar is. Tweedens is daar die werksdokument Has socialism failed? wat deur Joe Slovo opgestel is vir diskussie binne die SAKP. In beide hierdie dokumente word daar direk gereageer op die krisis waarin sosialisme en kommunisme binne die Oos-blok beland het.

Ten grondslag van beide hierdie dokumente lê daar enersyds 'n waardering vir die proses van glasnost en perestroika wat deur Gorbachev geïnisieer is, maar andersyds tog ook weer 'n erkenning dat die gebeure in Oos-Europa sowel sosialisme as kommunisme wêreldwyd in 'n krisis gedompel het. Die reaksie van die SAKP op hierdie krisis kan as rehabiliterend beskryf word. Die krisis van kommunistiese sosialisme is volgens die SAKP nie veroorsaak deur die filosofie onderliggend daaraan nie, maar deur die verkeerde bestuur en toepassing daarvan. Kommunistiese sosialisme moet daarom nie verwerp word nie, maar moet van die ondemokratiese en diktatoriale toepassing daarvan gesuiwer word. Hierdie houding teenoor die krisis van kommunisme blyk duidelik wanneer Slovo sê:

The scrious errors that emerged in the practice of existing socialism are not rooted in the basic lenets of Marxist revolutionary science. They are the result of distortions and misapplications. They were not incvitable (Slovo, 19\%)b:10).

Die bevestiging van sy vertroue in die potensiaal van kommunisme, blyk eweneens wanneer hy verklaar dat

We belicve, however, that the theory of Marxism, in all its essential respects, remains valid and provides an indespensable theoretical guide to achicve a socicty free of all forms of exploitation of person by person (Slovo, 1990b:15).

Hierdie keuse vir kommunistiese sosialisme ten spyte van die mislukking daarvan in die Oos-blok, spruit uit 'n diepgewortelde wantroue in, en afkeer van die kapitalistiese stelsel. Daar is in hoofsaak drie wesenstrekke wat volgens die SAKP essensieel tot die kapitalisme behoort en wat totaal onaanvaarbaar vir die SAKP is.

* Eerstens maak dit enige vorm van vrye demokrasie onmoontlik, aangesien die kapitaliste se ekonomiese magsposisie hulle in staat stel om die demokratiese politieke proses tot hulle eie voordeel te manipuleer (vgl. Slovo, 1990a:15).

* Tweedens word die kapitalisme van ontmensliking verwyt, aangesien dit profyt bo 
Die effek van Sowjet en Oos-Europese veranderings op kommunistiese denke

mense stel (vgl. Van der Merwe, 1990:22) en

* derdens word daarop gewys dat die welvarende Eerstewêreldkapitaliste, slegs by die grasie van 'n uitgebuite Derdewêreld kan bestaan. Uitbuiting van die arm dele van die bevolking en die arm dele van die wêreld, vorm dus die basis waarop die kapitalistiese winste behaal word (vgl. Van der Merwe, 1990:22).

Die feit dat die SAKP in sy twee jongste beleidsdokumente sy vertroue in kommunistiese sosialisme onomwonde bevestig het, beteken egter nie sonder meer dat die Oosblokveranderinge geen effek op die SAKP se denke gehad het nie. Inteendeel, dit blyk dat die SAKP die politieke lesse van die Oos-blok besonder ernstig opgeneem het. Die ekonomiese lesse van die Oos-blok daarenteen het besonder min effek op die SAKP se ekonomiese strategie gehad.

Wat die politieke effek van die Oos-blokveranderinge betref, gee die SAKP toe dat die demokratiseringsproses wat via glasnost in die Sowjet-Unie begin het, ook 'n merkbare verandering in hulle eie benadering teweeggebring het (vgl. SAKP, 1990:8). Die SAKP skryf die verval van kommunisme en die feit dat dit nie die populêre steun van die massas kon wen nie, toe aan die feit dat die demokrasie gaandeweg in die Oos-blok verval het. Verteenwoordigende strukture binne en buite die Party het verword tot transmissiebande vir die besluite wat deur 'n ongekontroleerde magselite geneem is. Juis hierdie ondemokratiese werkwyse het enersyds die geloofwaardigheid van die eenpartyregering in gedrang gebring en andersyds tot die politieke vervreemding van die werkersmassa aanleiding gegee (vgl. Slovo, 1990a:18-22).

In reaksie op hierdie negatiewe evaluering van die gebrek aan demokrasie in die Oosblok, bevestig die SAKP dat daar geen spanning tussen kommunisme en demokrasie bestaan nie. Trouens, kommunisme, asook die voorafgaande fase van sosialisme, is juis 'n poging om die demokrasie uit te brei en te verdiep. Die strategie van die SAKP moet daarom, sowel in die vroeë fase van politieke emansipasie, as in die latere fase van ekonomiese emansipasie, van demokrasie deursuur wees.

Hierdie openlike verbinding tot demokrasie blyk onder meer daarin dat die SAKP sigself verbind tot ' $n$ veelpartydemokrasie in beide fases van die kommunistiese revolusionêre proses. Slovo (1990a: 28) stel dit onomwonde dat "we remain protagonists of multi-party post-apartheid democracy both in the national democratic and the socialist phases". Onder demokrasie verstaan die SAKP vrye, gereelde en veelpartyverkiesings waarin die SAKP net soos enige ander politieke party sy mandaat van die breë bevolking moet verkry. Ook ten opsigte van die rol van die SAKP as die voorhoedeparty van die werkersrevolusie, bevestig die SAKP dat hierdie rol nie bloot deur aanspraak verdien kan word nie, maar dat hierdie rol demokraties deur die SAKP 
verdien moet word - dit moet dus via die stembus hierdie rol toegesê word.

Hierdie keuse vir demokrasie moet egter nie sonder meer geïnterpreteer word as ' $n$ keuse vir onderhandeling nie. Die SAKP se houding ten opsigte van onderhandeling is veel meer genuanseerd. Alhoewel onderhandeling nie uitgesluit is nie, is dit aan 'n reeks voorwaardes onderworpe waarvan die belangrikste is dat die werkersklas se belange asook die moontlikheid tot die skepping van 'n sosialistiese staat nie gekompromitteer mag word nie (vgl. Evans \& Gqubule, 1989 en Niddrie, 1989:22).

In teenstelling met die redelik diepgaande demokratisering van die SAKP se politieke strategie as gevolg van die Oos-blokveranderinge, behou die SAKP sy ekonomiese strategie bykans onveranderd ten spyte van die Oos-blokveranderinge. Die SAKP is wel bereid om in die eerste fase van die kommunistiese revolusie sy sosialistiese ekonomiese strategie op die agtergrond te skuiwe ter wille van die vorming van breë politieke alliansies. Dit is egter slegs 'n taktiese oorweging ten einde nie steun vir die nasionale demokratiese beweging te vervreem nie (vgl. SAKP, 1989:37).

Sodra die politieke oorwinning egter behaal is, stel die SAKP sigself ten doel om onverwyld vir die realisering van 'n kommunistiese sosialistiese Suid-Afrika te werk. Hierdie verbintenis tot kommunisme blyk weinig af te wyk van die klassieke Marxisties-Leninistiese denke. Die probleem van die Suid-Afrikaanse samelewing word steeds as kapitalisme getipeer - weliswaar as 'n besondere soort kapitalisme naamlik "colonialism of a special type" (vgl. SAKP, 1989:19). Die samelewing word steeds in twee klasse verdeel en die werkersklas gesien as die stukrag van historiese verandering. Boonop word sosialisme en kommunisme steeds as die enigste oplossing vir die probleem van kapitalistiese vervreemding beskou (vgl. Slovo, 1990a:15).

Hieruit blyk dit dat die proses van ekonomiese herstrukturering wat in die Sowjet-Unie en Oos-Europa aan die gang is, min invloed op die SAKP het. Dit blyk dus dat glasnost (demokrasie) 'n veel vriendeliker ontvangs as perestroika (ekonomie) by die SAKP geniet.

\subsection{Swartbewussynsdenke}

Binne die geledere van die swartbewussynsgroepe in Suid-Afrika is AZAPO die mees uitgesproke pro-sosialistiese groep. Hulle verbondenheid tot sogenaamde 'scientific socialism' is sowel voor as na die Oos-blokveranderinge onomwonde uitgespel. Onder 'scientific socialism' bedoel hulle dan onder andere die beëindiging van privaatbesit ten opsigte van grond asook die nasionalisering van industrieë, banke, myne en so meer. Hierdie nasionalisering moet dan aangevul word met sosialisering ten einde 
Die effek van Sowjet en Oos-Europese veranderings op kommunistiese denke

werkersbeheer oor die ekonomie te verseker (vgl. Jones, 1987:22). Die agent van hierdie revolusionêre proses moet die swart werkersklas wees.

Dit blyk dat AZAPO sodanig ideologies verhard is dat hulle geen lesse uit die Oosblokveranderings kan of wil leer nie. By monde van sy president dr. Itumeleng Jerry Mosala het AZAPO dan ook by die negende nasionale kongres van die organisasie wat in Mart 1990 plaasgevind het, sy onwrikbare vertroue in "scientific socialism" herbevestig (vgl. Pela, 1990:6). Die enigste les wat AZAPO skynbaar uit die Oosblokveranderinge geleer het, was dat sosialisme van die begin af radikaal en kompromisloos toegepas moet word. Na sy mening was die Oos-Europese state nooit werklik sosialisties nie. Juis om hierdie rede is hy van mening dat

All true socialists should welcome the recent fall of the pseudo-socialist totalitarian regimes in Eastern Europe as they were paying the price for prescribing socialism for the masses and feudal-capitalism for themselves (Anon, 19\%:6).

Hieruit blyk dit dat Mosala wil argumenteer dat sosialisme nie in Oos-Europa gefaal het nie, aangesien dit in die eerste plek nooit daar toegepas is nie. In terme van die argumentasie is die geskiedenis van sosialisme dus onbevlek aangesien dit nog nooit êrens toegepas is nie. So 'n puristiese benadering verraai normaalweg 'n ekstreme ideologiese stellinginname.

\section{SIOTOPMERKINGS}

Die twee kante van die strategie wat ontwerp is om die vervreemding wat deur kommunistiese staatsosialisme veroorsaak is, teen te werk, naamlik demokrasie en 'n markgeoriënteerde ekonomie, het beslis ook 'n blywende impak op die grootste deel van die nie-parlementêre linkse politiek gemaak.

Demokratiese waardes in hierdie geledere het of 'n groter inslag gevind of is ten minste verstewig deur die veranderinge in die Oos-blok. Veral twee perspektiewe blyk van blywende betekenis te wees. Eerstens is besef dat ondemokratiese regeringstelsels ook binne 'n sosialistiese of kommunistiese kader tot magsmisbruik kan lei. Demokratiese kontrole oor die regering is daarom noodsaaklik om tirannie te voorkom. Tweedens is besef dat geen regering 'n natuurlike aanspraak op legitimiteit het nie. Politieke legitimiteit kan alleen die eindresultat van 'n vrye demokratiese politieke proses wees.

Betreffende die klem op die mark, het die Oos-blokverandering weliswaar nie tot die prysgawe van sosialisme gelei nie, maar het dit ten minste tot 'n meer verantwoordelike debat oor sosialisme aanleiding gegee - al is dit dan slegs in die geledere van die 
ANC en sy binnelandse vennoot COSATU. Die feit dat 'n ideologiese keuse vir sosialisme vervang is met 'n verantwoordelike debat oor 'n ekonomie wat enersyds groei kan stimuleer en andersyds ook in die basiese sosiale behoeftes van die totale bevolking kan voorsien, moet verwelkom word. Die vrae wat via hierdie ontwikkeling die sleutelvrae van die ekonomiese debat in ANC-geledere geword het, blyk legitieme ekonomiese, maar ook politieke vrae te wees. In die woorde van Michael Walzer het die belangrikste vrae in die betrokke debat nou geword: 'wat kan geld koop?' en 'wat kan geld nie koop nie?' (vgl. Walzer, 1983:97-108). Dit is nie te ontken dat geld enersyds buite die sfeer van die mark aangewend kan word om politieke mag en in vloed te bekom nie. Andersyds is dit ook so dat 'n gebrek aan geld ook mense kan kortwiek on volledige deelnemers aan die sosiale gemeenskap te word. 'n Ekonomiese debat wat albei hierdie uiterstes wil voorkom, maar andersyds aan die mark sy normale funksie en ruimte wil toeken, is beslis 'n positiewe ontwikkeling, nie net in terme van gesonde ekonomiese beginsels nie, maar ook in terme van morele besinning. Walzer (1983:109) se raak opmerking vat dit miskien die beste saam:

The market is a zone of the city, not the whole city. But it is a great mistake, I think, when people, worried about the tyranny of the market, secks its entirc abolition. It is one thing to clear the temple of the traders, quite another to clear the strects.

\section{BIBLIOGRAFIE}

ADAM, H. 19\%). Slovo's problems: A Stalinist past and a democratic future. Business Day: 8. April, 12. ANONIEM 1990a. UCT man lempers praise of De Klerk. The Siar: 6. March, 3.

ANONIEM 1990b. UDF decision to nationalise. New Nation: 25. March, 8

DAVIES-WEBB, W. 1989. Lenin's infantile disorder: The rise of Trotskyism in South Alrica. South African Freedom Review, 2(3) 71-100.

ERWIN, A. 1\%). The challenge of Europe: Towards a post apartheid economy. Die Suid-Afrikaan: 2426. Fcbr.

EVANS, G. \& GOUBULE, T. 1989. Goodbyc Joc Stalin. Weckly Mail: 13 Aug., 31.

(ILASER, D. 1988. Democracy, socialism and the future. Work in Progress, 56/57:28-30.

GORBACHEV, M. 1987. Perestroika. Londen : Collins.

JONES, P. 1987. Struggle for a socialist A\%ania. Marxist Review: 19-22. Jan.

LATEY, M. 1989. The general crisis of socialism. The World Today, 45:(8-9):131-134

NAGORSKI, A. 1990. The middle way is an illusion. Newsweek: 13. March, 5

NIDDRIE, D. 1989. A ncw party programme. Work in Progress, 60:19-23. Aug.-Sept.

PEDERSON, D. 1990). The Swedish model. Newsweek: 8-12. March, 5.

PELA, M. 1900. We must not be seduced-Mosala. Sowetan: 6. March, 14.

SAKP 1989. The path to power.

SLOVO, J. 1990a. Has socialism failed? South African Labour Bulletin, 14(6):11-28.

SLOVO, J. 19\%)b. Restoring socialism. New Nation: 10-11. Oct, 3.

STOJANOVIC, S. 1988. Perestroika: From Marxism and Bolshevism to Gorbachev. New York : Prometheus Books.

VAN DER MERWE, E. 1990. Slovo's red vision is intact. The Star: 22. March, 3. 
Die effek van Sowjet en Oos-Europese veranderings op kommunistiese denke

VAN HOLDT, K. 1990. Class struggle and the mixed cconomy. South African Labour Bulletin, 14(6):45-

WALZER, M. 1983. Spheres of justice. Oxford : Basil Blackwcll. 